\title{
Macrolide Antibiotics like Azithromycin InCREASE LipopolysaCCHARIDE-INDUCED IL-8 Production BY HuMAN GingIVAL FIBROBLASTS
}

\author{
A. Kamemoto ${ }^{1, *}$, T. Ara ${ }^{1,2, *}$, T. Hattori ${ }^{1,2}$, Y. Fujinami ${ }^{2}$, Y. Imamura ${ }^{1,2}$, P.-L. Wang ${ }^{1,2}$ \\ ${ }^{1}$ Department of Hard Tissue Research, Graduate School of Oral Medicine, Matsumoto Dental University; \\ ${ }^{2}$ Department of Pharmacology, Matsumoto Dental University, Hirooka, Shiojiri, Nagano, Japan
}

\begin{abstract}
Objective: Macrolide antibiotics are reported to modulate the production of cytokines in various type of cells. We examined the effect of macrolide antibiotics on inflammatory cytokines (IL-6 and IL-8) and chemical mediator $\left(\mathrm{PGE}_{2}\right.$ ) and also matrix metalloproteinases (MMPs) productions by human gingival fibroblasts (HGFs) treated with lipopolysaccharide (LPS).

Methods: The effect of macrolide antibiotics [erythromycin (EM), azithromycin (AZM) and josamycin (JOM)] on HGFs proliferation were examined by MT'T assay. HGFs were treated with LPS from Porpbyromonas gingivalis (PgLPS) and macrolide antibiotics, and IL-6, IL- 8 and PGE 2 levels were evaluated by ELISA. MMPs were detected by gelatin zymography.

Results: AZM slightly but significantly decreased HGFs proliferation, while EM and JOM did not affected. AZM increased PgLPS-induced IL-8 production dose-dependently, while AZM did not alter IL-6 and $\mathrm{PGE}_{2}$ productions. EM and JOM did not altered PgLPS-induced IL-6, IL-8 and PGE 2 productions. All macrolide antibiotics did not alter MMPs production. These results indicate that macrolide antibiotics have no direct anti-inflammatory effect. However, the use of the inhibitors of cell signaling pathway failed to reveal the mechanism that AZM enhanced PgLPS-induced IL-8 production.

Conclusion: These results suggest macrolide antibiotics have an indirect anti-inflammatory effect as a result of their antimicrobial properties. Because AZM increased LPS-induced IL- 8 production by HGFs, the possibility is considered that neutrophils may be migrated to periodontal tissue and phagocytize the periodontopathic bacteria more efficiently.
\end{abstract}

Key words: macrolide antibiotics, azithromycin, human gingival fibroblast, interleukin-8, anti-inflammatory effect

*Akira Kamemoto and Toshiaki Ara contributed equally to this work.

\section{INTRODUCTION}

Caries and periodontal disease are two major oral diseases and are considered to be biofilm infections diseases [1]. In particular, periodontal disease is highly prevalent and can affect most of the world population. Periodontal disease is accompanied by inflammation of the gingiva and destruction of periodontal tissues, leading to alveolar bone loss in severe clinical cases.

To date, the effects of macrolide antibiotics on periodontal disease are examined in vitro and in vivo. Macrolide antibiotics are be classified into 14-, 15and 16-membered ring. The representative drugs in their groups are erythromycin (EM), azithromycin (AZM) and josamycin (JOM), respectively. In particular, AZM has a good tissue penetration property [2-5] and inhibits biofilm formation made of Pseudomonas aeruginosa [6]. We have reported that macrolide antibiotics, erythromycin (EM), azithromycin (AZM) and josamycin (JOM), inhibit biofilm formation made from Streptococcus gordonii and Porphyromonas gingivalis and that, EM and AZM, but not JOM, destroy formed biofilm in vitro [7]. Moreover, our group reported that AMZ shortens the duration of treatment for aggressive periodontitis [8]. Other than our reports, several groups showed the usefulness of AMZ for the treatment of periodontal disease in clinical and bacterial viewpoints [9-12]. These reports suggest that the combined application of macrolide antibiotics, in particular $A M Z$, is effective for periodontal disease.

Recently, several reports showed that macrolide antibiotics modulate the production of inflammatory cytokine. AZM increase cytokines production in whole blood and alveolar macrophages [13] and bronchial epithelial cells [14]. In contrast, AZM decreases cytokines production in endothelial cells [15], airway epithelial cell $[16,17]$ and smooth muscle cells [18] and plasma from LPS-treated mice [19]. In particular, the latter phenomena mean that macrolide antibiotics have direct anti-inflammatory effect. Therefore, we consider the examination is interesting whether macrolide antibiotics modulate inflammatory response in periodontal disease. 
Human gingival fibroblasts (HGFs) are the most prominent cells in periodontal tissue. And HGFs produce inflammatory cytokines such as interleukin (IL)-6 and IL- 8 and inflammatory chemical mediators such as prostaglandin $\mathrm{E}_{2}\left(\mathrm{PGE}_{2}\right)$ when $\mathrm{HGF}$ sere treated with lipopolysaccharide (LPS) [20-23]. Therefore, we regard this experimental system, in which HGFs were treated with LPS, as in vitro periodontal disease model. Moreover, because HGFs sustain to produce IL-6

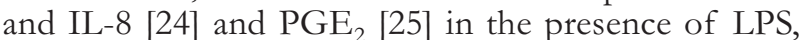
we consider that the examinations of effect on HGFs, as well as monocytes and macrophages, are important in the study on periodontal disease.

Using this in vitro model, we examined the effect of macrolide antibiotics (EM, AZM and JOM) on LPSinduced IL-6, IL-8 and PGE 2 production. Moreover, we examined the production of matrix metalloproteinases (MMPs) which play important roles in tissue degradation and periodontal disease.

\section{Materials AND Methods}

\section{ReAGENTS AND CELLS}

Erythromycin (EM), azithromycin (AZM) and josamycin (JOM) were obtained from Nihon SiberHegner (Tokyo, Japan), Pfeizer Japan (Tokyo, Japan) and Astellas Pharma (Tokyo, Japan), respectively. All antibiotics were dissolved in methanol at $100 \mathrm{mg} / \mathrm{ml}$ and added to culture media at final concentration of $0.1,1$ and $10 \mu \mathrm{g} / \mathrm{ml}$. LPS from Porphyromonas gingivalis 381 (PgLPS) was provided by Drs. Tatsuji Nishihara and Nobuhiro Hanada (National Institutes of Public Health, Wako, Japan). PD98059 [mitogen-activated protein kinase kinase (MAPKK/MEK) inhibitor; Sigma, St. Louis, MO], SP600125 [c-Jun Nterminal kinase (JNK) inhibitor; Sigma], SB202190 (p38 MAPK inhibitor; Sigma), H-89 [protein kinase A (PKA) inhibitor; Sigma], wortmannin [phosphoinositide 3-kinase (PI3K) inhibitor; Sigma], U-73122 [phospholipase Cg (PLC $\gamma$ ) inhibitor; Sigma] were dissolved in dimethyl sulfoxide (DMSO). Pyrrolidin

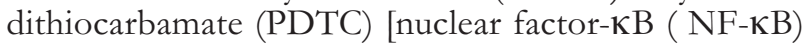
inhibitor; Nacalai tesque, Kyoto, Japan] were dissolved in sterile water.

HGFs were prepared as described previously [26]. HGFs were maintained in Dulbecco's modified Eagle's medium (D-MEM, Sigma) containing 10\% heat-inactivated fetal calf serum (FCS), 100 units $/ \mathrm{ml}$ penicillin and $100 \mathrm{mg} / \mathrm{ml}$ streptomycin, at $37^{\circ} \mathrm{C}$ in a humidified atmosphere of $5 \% \mathrm{CO}_{2}$. This study was approved by the Ethical Committee of our institution. Informed consent was obtained from each subject for the collection of HGFs.

\section{MTT ASSAY}

The numbers of cells were measured by MT'T assay. In brief, the media were removed by aspiration and the cells were treated with $0.5 \mathrm{mg} / \mathrm{ml}$ dimethylthiazol-2-yl2,5-diphenyltetrazolium bromide (MT'T, Sigma) in culture medium for $4 \mathrm{~h}$ at $37^{\circ} \mathrm{C}$. After washed with PBS once, isopropanol/ $0.04 \mathrm{M} \mathrm{HCl}$ was added and optical density $\left(\mathrm{OD}_{570}\right)$ were measured using microplate reader (Model 550; Bio-Rad, Hercules, CA).

\section{Cytokine Measurement by EnZyme-Linked EMmunosorbent Assay (ELISA)}

HGFs (10,000 cells/well) were seeded in 96-well plates (AGC Techno Glass Co., Chiba, Japan) and incubated in serum-containing medium at $37^{\circ} \mathrm{C}$ overnight. Then, the cells were treated with various concentrations of antibiotics $(0,0.1,1$ and $10 \mu \mathrm{g} / \mathrm{ml})$ in the absence or presence of PgLPS $(10 \mathrm{ng} / \mathrm{ml})$ for $24 \mathrm{~h}(200 \mu \mathrm{l}$ per each well). In the experimental using inhibitors of cell signaling were used, the cells were pretreated with PD98059 (20 $\mu \mathrm{M})$, SP600125 (20 $\mu \mathrm{M}), \quad$ SB202190 $(20 \mu \mathrm{M}), \quad$ H-89 $(10 \mu \mathrm{M})$, wortmannin $(20 \mathrm{nM}), \mathrm{U}-73122(2 \mu \mathrm{M})$ or equal volume of DMSO (control) for $60 \mathrm{~min}$, followed by treatment with the combination of PgLPS, (0 or $10 \mathrm{ng} / \mathrm{ml})$, AZM $(10 \mu \mathrm{M})$ and each inhibitor (the same concentration as pretreatment) for $24 \mathrm{~h}$. Using PDTC $(100 \mu \mathrm{M})$, the equal volume of sterile water ( $1 / 500$ volume) were added as a control. The numbers of cells were measured using MTT assay. The concentrations of IL-6, IL-8 and prostaglandin $\mathrm{E}_{2}\left(\mathrm{PGE}_{2}\right)$ in the culture supernatants were measured by ELISA according to the manufactures' instructions (IL-6 and IL-8, Biosource International Inc., Camarillo, CA; PGE 2 , Cayman Chemical, Ann Anbor, MI), and were adjusted by the number of remaining cells.

\section{ZYMOGRAPHY}

Cell culture supernatants as above were subjected to gelatin (for MMP-2 and MMP-9) or casein (for MM-1 and MMP-3) zymography according to the method described previously [27, 28]. Cell supernatants $(10 \mu \mathrm{l})$ were mixed with $3 \mathrm{x}$ sample buffer [150 mM Tris-HCl (pH6.8), 6\% SDS, 30\% glycerol and $1 \%$ bromophenol blue] and fractionated in $10 \%$ polyacrylamide gel containing $0.1 \%$ gelatin or casein under non-reducing conditions at $4{ }^{\circ} \mathrm{C}$. The gel was shaken in $10 \mathrm{mM}$ Tris-HCl, pH7.5, 2.5\% Triton X-100 at room temperature for $30 \mathrm{~min}$ twice to remove SDS. Then the gel was shaken in $50 \mathrm{mM}$ Tris- $\mathrm{HCl}$ (pH7.5) for $10 \mathrm{~min}$ at room temperature, followed by shaking gently in $20 \mathrm{mM}$ Tris- $\mathrm{HCl}$ (pH7.5), $200 \mathrm{mM} \mathrm{NaCl}, 5$ $\mathrm{mM} \mathrm{CaCl}, 0.02 \%$ sodium azide] at $37^{\circ} \mathrm{C}$ for $20 \mathrm{~h}$. The gel was fixed in 50\% methanol and $10 \%$ acetic acid, stained with coomasie brilliant blue R-250 and destained.

\section{Statistical ANALYSis}

Data are presented as means \pm standard deviation (SD). Differences between control group and experimental groups were evaluated by Dunnett method (Fig. 1). Differences between groups were evaluated by the pairwise comparison test corrected with Holm method (4 null hypotheses, without PgLPS vs. with PgLPS; $3+3$ null hypotheses without antibiotics vs. with $0.1,1$ and $10 \mu \mathrm{g} / \mathrm{ml}$ of antibiotics in the absence or presence of PgLPS; total 10 null hypotheses, Fig. 2). All computations were performed with the statistical program R [29]. Values with $\mathrm{P}<0.05$ were considered as significantly different. 


\section{RESULTS}

\section{The Effect of Macrolide Antibiotics on HGFs} PROLIFERATION

First, we examined the effect of macrolide antibiotics on HGFs proliferation. The concentrations of macrolide antibiotics were determined based on the clinical report that AZM concentration in periodontal tissue with the usual use of AMZ (500 mg/day for 3 days) are $2-3 \mu \mathrm{g} / \mathrm{g}$ tissue [30]. At day 3, any antibiotics in all concentration showed no effect on HGFs proliferation. At day 7, EM and JOM showed no effect on HGFs proliferation at up to $10 \mu \mathrm{g} / \mathrm{ml}$. AZM also showed no effect on HGFs proliferation at up to 1 $\mu \mathrm{g} / \mathrm{ml}$ but suppressed slightly, but significantly, HGFs proliferation at $10 \mu \mathrm{g} / \mathrm{ml}$ (Fig. 1).
The Effect of Macrolide Antibiotics on IL-6, IL-8 AND PGE 2 Production

We examined the effects of antibiotics in in vitro periodontal disease model. When HGFs were treated with PgLPS and macrolide antibiotics for $24 \mathrm{~h}$, the viability of HGFs were hardly affected by MT'T assay (data not shown). The concentrations of IL-6, IL- 8 and PGE 2 were measured and adjusted by the results of MTT assay. In the absence of PgLPS, all macrolide antibiotics did not affect IL-6, IL-8 and PGE 2 production (Fig. $2)$. When HGFs were treated with $10 \mathrm{ng} / \mathrm{ml}$ of PgLPS, HGFs produced large amount of IL-6, IL-8 and $\mathrm{PGE}_{2}$. EM and JOM at up to $10 \mathrm{mg} / \mathrm{ml}$ did not affected LPS-induced IL- 6 and PGE 2 production (Fig. $2 \mathrm{~A}$ and $\mathrm{C})$. However, AZM increased LPS-induced
A

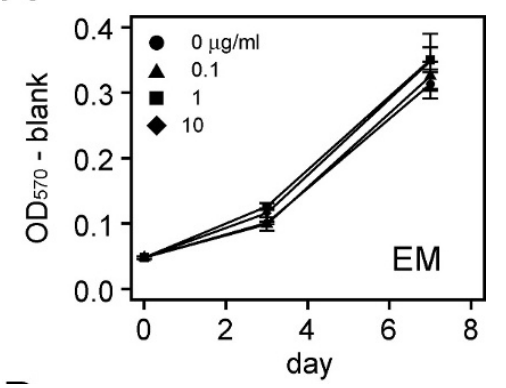

B

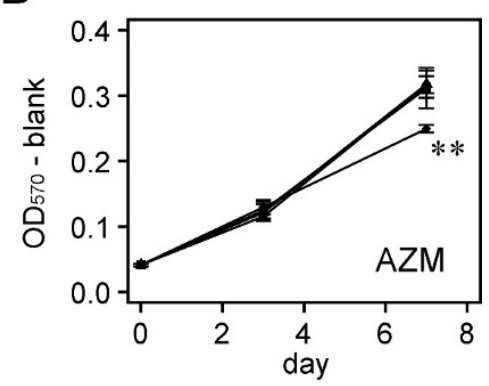

C

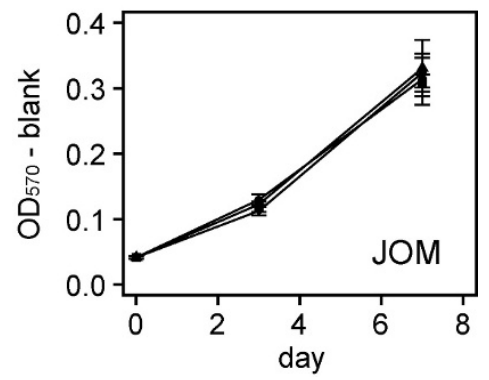

Fig. 1. The effect of macrolide antibiotics on HGFs proliferation. HGFs were plated in 96-well microplate at 2,000 cells/well and were added the media containing macrolide antibiotics $(0,0.1,1$ and $10 \mu \mathrm{g} / \mathrm{ml})$. MTT assay was performed at day 0,3 and 7 days. ${ }^{* *} \mathrm{P}<0.01$ (Dunnett method).

A

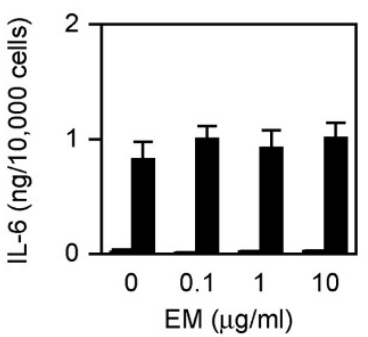

B

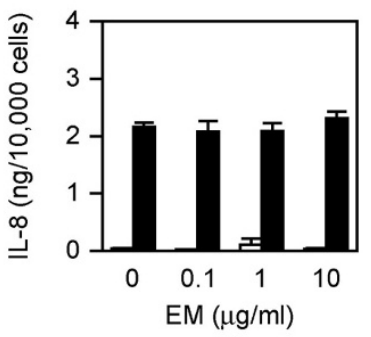

C

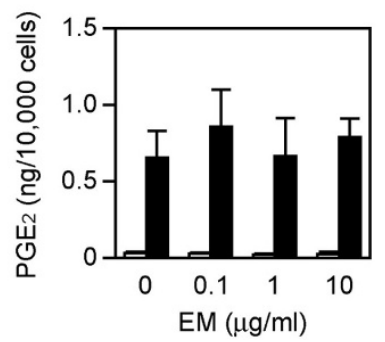

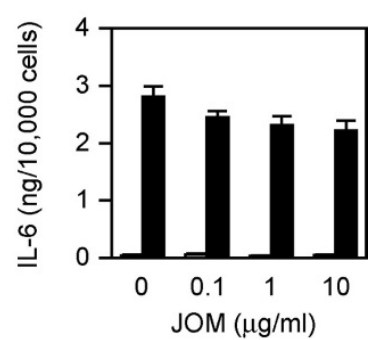
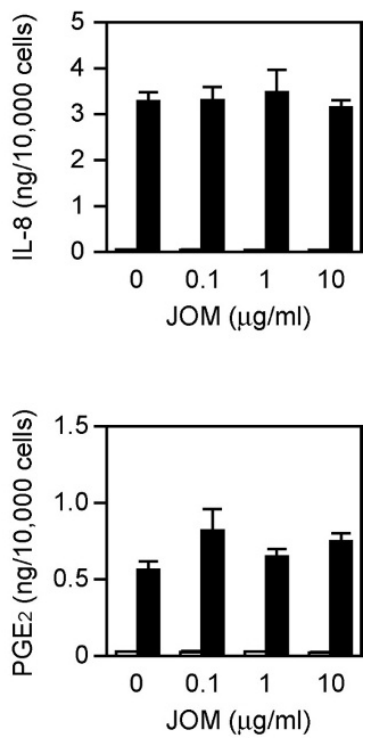

Fig. 2. The effects of macrolide antibiotics on the production of IL-6, IL-8 and PGE 2 . HGFs were treated with the combinations with PgLPS $(0$ and 10 $\mathrm{ng} / \mathrm{ml}$ ) and macrolide antibiotics $(0,0.1,1$ and $10 \mu \mathrm{g} / \mathrm{ml})$ for $24 \mathrm{~h}$, and the concentrations of IL-6 (A), IL-8 (B) and PGE 2 (C) were measured by ELISA. The concentrations were adjusted by the cell numbers and expressed as per 10,000 cells. $* \mathrm{P}<$ $0.05,{ }^{* *} \mathrm{P}<0.01$ (pairwise comparison corrected with Holm method, 10 null hypotheses). Open bars, treatment without PgLPS; closed bars, treatment with $10 \mathrm{ng} / \mathrm{ml}$ of PgLPS. 
IL-8 production in a dose-dependent manner (Fig. 2B). Similar results were obtained using human skin fibroblast TIG-103 cells (data not shown). These results indicate that AZM, but not EM and JOM, affects only IL-8 production by HGFs.

\section{The Effect of Macrolide Antibiotics on MMPs PRODUCTION}

Next, we examined the effect of macrolide antibiotics on MMPs production by HGFs. When HGFs were treated with the combination with PgLPS (0 and 10 $\mathrm{ng} / \mathrm{ml}$ ) and macrolide antibiotics $(0,0.1,1$ and 10 $\mu \mathrm{g} / \mathrm{ml})$, the bands of proMMP-2 and active MMP-2 were very similar (Fig. 3). No bands of MMP-1, MMP3 and MMP-9 were observed in HGFs (data not shown). These results indicated that PgLPS and macrolide antibiotics do not affect MMPs production.

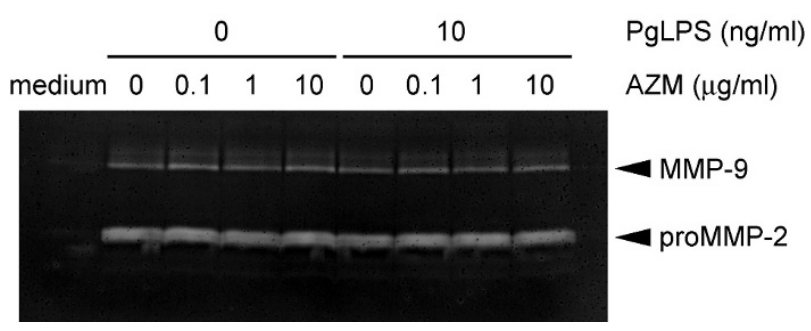

Fig. 3. The effects of macrolide antibiotics on MMPs. HGFs were treated with the combinations with PgLPS $(0$ and 10 $\mathrm{ng} / \mathrm{ml}$ ) and $\operatorname{AZM}(0,0.1,1$ and $10 \mu \mathrm{g} / \mathrm{ml})$ for $24 \mathrm{~h}$, and the cell supernatants were subjected to gelatin zymography.

The Examination of Mechanism that AZM Enhances IL-8 Production Using Cell Signaling INHIBITORS

At last, we examined what signal pathway AZM activates using cell signaling inhibitors of MEK/ERK (PD98059), JNK (SP600125), p38 MAPK (SB202190), NF-кB (PDTC), PKA (H-89), PI3K (wortmannin) and PLC $\gamma$ (U-73122). If AZM increases IL-8 production by the activation of these cell signalings, their inhibitors will abolish its increased IL- 8 production. Namely, it is predicted that when HGFs were treated with these inhibitors, IL-8 level from PgLPS+AZMtreated cells is equal to that from PgLPS-treated cells.

In DMSO-treated cells (control), AMZ increased PgLPS-induced IL-8 production approximately 1.4fold (Fig. 4A). When HGFs were treated with PD98059, IL-8 levels are almost equal to control in PgLPS- or PgLPS+AZM-treated cells (Fig. 4A). When HGFs were treated with SP600125, PgLPS-induced IL-8 production was increased compared with control and PgLPS+AZM-induced IL-8 production was slightly increased (Fig. 4A). When HGFs were treated with SB202190, both PgLPS- and PgLPS+AZM-induced IL-8 productions were decreased. However, the ratio of IL-8 level treated with PgLPS+AZM to that with AZM ratio is approximately 1.4 and quite equal to that in control (Fig. 4A). When HGFs were treated with $\mathrm{H}-89$, PgLPS-induced IL-8 production was de-
A

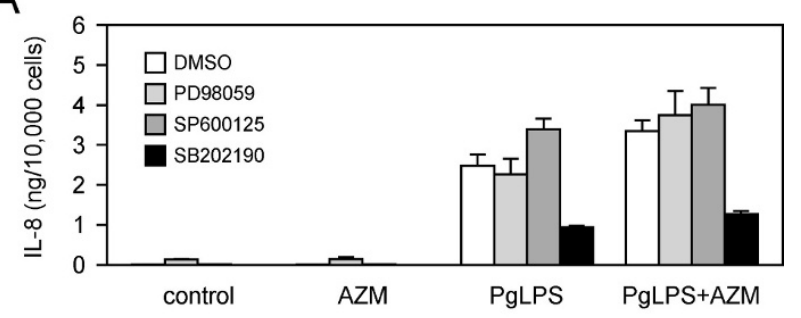

$\mathrm{B}$

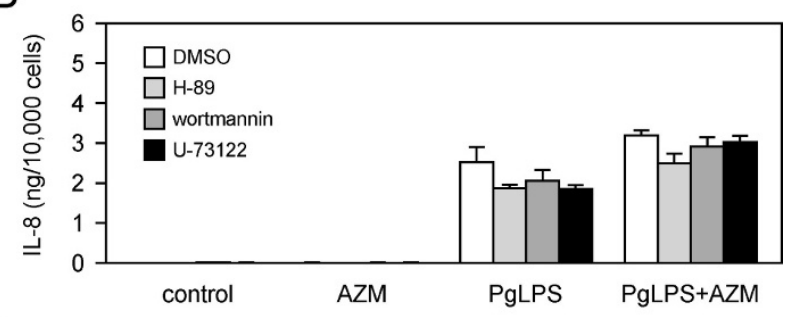

C

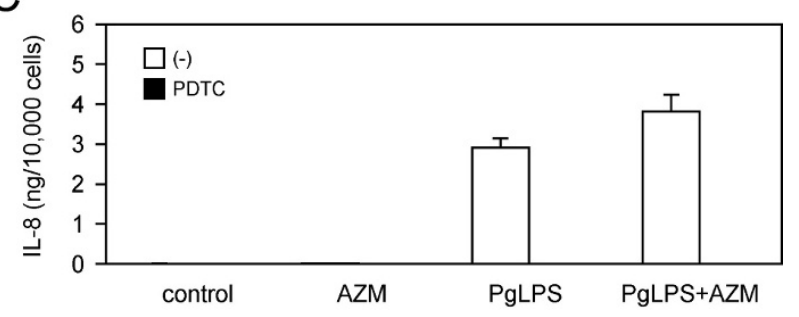

Fig. 4. The effects of cell signaling inhibitors on PgLPS- and PgLPS + AZM-induced IL-8 production. HGFs were pretreated with inhibitors, and treated with the combination of PgLPS (0 and $10 \mathrm{ng} / \mathrm{ml})$, AZM $(0$ and $10 \mu \mathrm{g} / \mathrm{ml})$ and each inhibitor. IL-8 levels were measured by ELISA. The concentrations were adjusted by the cell numbers and expressed as per 10,000 cells. (A) PD98059 $(20 \mu \mathrm{M})$, SP600125 $(20 \mu \mathrm{M})$ and SB202190 $(20 \mu \mathrm{M})$; (B) H-89 $(10 \mu \mathrm{M})$, wortmannin $(20 \mathrm{nM})$ and $\mathrm{U}-73122(2 \mu \mathrm{M})$; (C) PDTC $(100 \mu \mathrm{M})$.

creased and PgLPS+AZM-induced one was slightly decreased compared to their controls (Fig. 4B). When HGFs were treated with wortmannin or U-73122, PgLPS-induced IL- 8 production was decreased but PgLPS+AZM-induced one was nearly equal to control (Fig. 4B). When HGFs were treated with PDTC, no IL-8 production was observed (Fig. 4C). These results indicate that all inhibitors we examined did not fulfill the prediction.

\section{DisCUSSION}

LPS-treated HGFs produce inflammatory cytokines such as IL-6 and IL-8 and inflammatory chemical mediators such as $\mathrm{PGE}_{2}$ [20-23]. IL-6, IL-8 and PGE 2 play important roles in inflammatory responses and tissue degradation. IL- 6 has the ability to induce osteoclastogenesis [20, 31]. IL-8 acts as a chemoattractant for neutrophils [32] that produce proteases such as cathepsin, elastase or MMP-8, leading to tissue degradation. $\mathrm{PGE}_{2}$ has several functions in vasodilation and the enhancement of vascular permeability and pain, the induction of osteoclastogenesis, and is believed to play important roles in inflammatory response and alveolar bone resorption in periodontal disease [33]. 
Therefore, we examined the effects of macrolide antibiotics on IL-6, IL- 8 and PGE 2 production.

Our data indicate that macrolides antibiotics did not decrease LPS-induced IL-6, IL-8 and $\mathrm{PGE}_{2}$ productions by HGFs. Rather, AZM increased IL- 8 production. Also macrolide antibiotics did not altered MMPs production. These results suggest that macrolide antibiotics do not have a direct anti-inflammatory effect. On the other hand, macrolide antibiotics show an antibacterial effect per se. We have reported that EM and AZM, but not JOM, destroy in vitro biofilm formed by Streptococcus gordonii and Porphyromonas gingivalis [7]. Therefore, macrolide antibiotics, in particular EM and AZM, have an indirect anti-inflammatory effect in periodontal disease as a result of antimicrobial properties. These findings are consistent with the previous report that AZM decreased bacteria-infected IL-6 production by hepatocyte HepG2 cells but did not affected IL-1 $\beta$-induced IL- 6 production, indicating antimicrobial properties of AZM but not a direct anti-inflammatory effect [34].

As well as this report [34], AZM did not decrease cytokine productions by HGFs. Rather, AMZ increased LPS-induced IL-8 production. Moreover, AZM increased LPS-induced IL-8 production in human skin fibroblast TIG-103 cells (data not shown). Therefore, the increase of IL- 8 production by AZM may be the property of fibroblasts.

The reason why AZM increases LPS-induced IL-8 production by HGFs is still unclear. It is reported that macrolide antibiotics activate MEK/ERK pathway and increases IL- 8 production in bronchial epithelial cells [14]. However, it is unlikely that AZM activates MEK/ERK in HGFs, because its inhibitor PD98059 fails to abolish the increased IL- 8 production by AZM in LPS-treated HGFs. For the similar reason, it is unlikely that AZM activates JNK, PKA, PI3K and PLC $\gamma$. Moreover, it is unlikely that AZM activates p38 MAPK because the ratio of IL- 8 level treated with PgLPS+AZM to that with AZM ratio in SB202190 (p38 MAPK inhibitor)-treated cells is quite similar to that in control, indicating that p38 MAPK inhibitor also fails to abolish the increased IL- 8 production by AZM. Because inhibition of NF- $\mathrm{KB}$ suppressed IL-8 production to basal level, the effect of AZM treat-

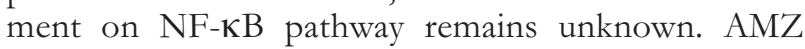
may activate $\mathrm{NF}-\kappa \mathrm{B}$ signaling.

AZM increases IL-8 production in HGFs and whole blood and macrophage [13], while AZM decreases in endothelial cells [15] and smooth muscle cells [18]. Because HGFs are most abundant in periodontal tissue and produce large amounts of IL- 8 , we consider that the overall IL- 8 level increases by AZM administration. Therefore, neutrophils may migrate into periodontal tissue and release the proteases (such as cathepsin, elastase and MMP-8). As a result of these events, inflammatory responses may exacerbate transiently. However, because neutrophils infiltrated into periodontal tissue phagocytize and decrease periodontopathic bacteria, the inflammatory response in periodontal tissue may cease rapidly.

However, initial preparation such as scaling and root planing is indispensable for the treatment of periodontal disease. Because periodontopathic bacteria are present in periodontal pockets (i.e. outside of the body) as a biofilm, hosts cannot exclude the biofilm by fibrous encapsulation and phagocytosis by neutrophils may be limited. Therefore, biofilm in periodontal pockets does not disappear unless dentists removed the biofilm artificially and physically. In the cases that biofilm or, if bacteria are killed, extracellular components of bacteria such as LPS and peptidoglycan remain in periodontal pocket, AZM administration may result in increased IL- 8 production and the exacerbation of inflammation.

Our results indicated only AMZ suppressed HGFs proliferation slightly in high concentration. However, this precise mechanism remains unknown although it is possible that the difference of structure among these antibiotics leads to these results. Nevertheless, we believe that suppression of HGFs proliferation by AZM yields little problem because the long-term administration of $A M Z$ is rare for the treatment of periodontal disease.

In summary, we demonstrated that macrolide antibiotics did not decrease LPS-induced IL-6, IL-8 and $\mathrm{PGE}_{2}$ production by HGFs. Rather, AZM increased LPS-induced IL- 8 production. These results suggest that macrolide antibiotics show no direct anti-inflammatory effect in periodontal disease, i.e. an indirect anti-inflammatory effect mediated by their antimicrobial properties.

Acknowledgment: We thank Drs. Tatsuji Nishihara and Nobuhiro Hanada for providing Porphyromonas gingivalis LPS. We also thank Associate Prof. Takashi Uematsu (Department of Oral and Maxillofacial Surgery) for HGFs preparation and Keiko Fujii for technical assistance. The study was supported by a Grant-in-Aid for Scientific Research from the Ministry of Education, Science, Sports (Code No. 18791390) and Culture of Japan and a Scientific Research Special Grant from Matsumoto Dental University.

\section{REFERENCES}

1. Costerton JW, Stewart PS and Greenberg EP. Bacterial biofilms: a common cause of persistent infections. Science (1999) 284: 1318-22

2. Girard AE, Girard D, English AR, Gootz TD, Cimochowski CR, Faiella JA, Haskell SL and Retsema JA. Pharmacokinetic and in vivo studies with azithromycin (CP-62,993), a new macrolide with an extended half-life and excellent tissue distribution. Antimicrob Agents Chemother (1987) 31: 1948-54

3. Baldwin DR, Wise R, Andrews JM, Ashby JP and Honeybourne D. Azithromycin concentrations at the sites of pulmonary infection. Eur Respir J (1990) 3: 886-90

4. Davila D, Kolacny-Babic L and Plavsic F. Pharmacokinetics of azithromycin after single oral dosing of experimental animals. Biopharm Drug Dispos (1991) 12: 505-14

5. Blandizzi C, Malizia T, Lupetti A, Pesce D, Gabriele M, Giuca MR, Campa M, Del Tacca M and Senesi S. Periodontal tissue disposition of azithromycin in patients affected by chronic inflammatory periodontal diseases. J Periodontol (1999) 70: 960-6

6. Tateda K, Comte R, Pechere JC, Kohler T, Yamaguchi K and Van Delden C. Azithromycin inhibits quorum sensing in Pseudomonas aeruginosa. Antimicrob Agents Chemother (2001) 45: 1930-3

7. Tamura A, Ara T, Imamura Y, Fujii $T$ and Wang PL. The effects of antibiotics on in vitro biofilm model of periodontal disease. Eur J Med Res (2008) 13: 439-45 
8. Fujii T, Wang PL, Hosokawa Y, Shirai S, Tamura A, Hikita K, Maida T, Ochi M and Baehni PC. Effect of systemically administrated azithromcycin in early onset aggressive periodontitis. Perio (2004) 1: 321-5

9. Smith SR, Foyle DM, Daniels J, Joyston-Bechal S, Smales FC, Sefton A and Williams J. A double-blind placebocontrolled trial of azithromycin as an adjunct to non-surgical treatment of periodontitis in adults: clinical results. J Clin Periodontol (2002) 29: 54-61

10. Mascarenhas P, Gapski R, Al-Shammari K, Hill R, Soehren S, Fenno JC, Giannobile WV and Wang HL. Clinical response of azithromycin as an adjunct to nonsurgical periodontal therapy in smokers. J Periodontol (2005) 76: 426-36

11. Gomi K, Yashima A, Nagano T, Kanazashi M, Maeda N and Arai T. Effects of full-mouth scaling and root planing in conjunction with systemically administered azithromycin. J Periodontol (2007) 78: 422-9

12. Haas AN, de Castro GD, Moreno T, Susin C, Albandar JM, Oppermann RV and Rösing CK. Azithromycin as an adjunctive treatment of aggressive periodontitis: 12months randomized clinical trial. J Clin Periodontol (2008) 35: 696-704

13. Kurdowska A, Noble JM and Griffith DE. The effect of azithromycin and clarithromycin on ex vivo interleukin-8 (IL-8) release from whole blood and IL-8 production by human alveolar macrophages. J Antimicrob Chemother (2001) 47: 867-70

14. Shinkai M, Foster GH and Rubin BK. Macrolide antibiotics modulate ERK phosphorylation and IL-8 and GMCSF production by human bronchial epithelial cells. Am J Physiol Lung Cell Mol Physiol (2006) 290: L75-85

15. Uriarte SM, Molestina RE, Miller RD, Bernabo J, Farinati A, Eiguchi K, Ramirez JA and Summersgill JT. Effect of macrolide antibiotics on human endothelial cells activated by Chlamydia pneumoniae infection and tumor necrosis factor-a. J Infect Dis (2002) 185: 1631-6

16. Cigana C, Nicolis E, Pasetto M, Assael BM and Melotti P. Anti-inflammatory effects of azithromycin in cystic fibrosis airway epithelial cells. Biochem Biophys Res Commun (2006) 350: 977-82

17. Cigana C, Assael BM and Melotti P. Azithromycin selectively reduces tumor necrosis factor alpha levels in cystic fibrosis airway epithelial cells. Antimicrob Agents Chemother (2007) 51: 975-81

18. Vanaudenaerde BM, Wuyts WA, Geudens N, Dupont LJ, Schoofs K, Smeets S, Van Raemdonck DE and Verleden GM. Macrolides inhibit IL17-induced IL8 and 8-isoprostane release from human airway smooth muscle cells. Am J Transplant (2007) 7: 76-82

19. Ivetic Tkalcevic V, Bosnjak B, Hrvacic B, Bosnar M, Marjanovic N, Ferencic Z, Situm K, Culic O, Parnham MJ and Erakovic V. Anti-inflammatory activity of azithromycin attenuates the effects of lipopolysaccharide administration in mice. Eur J Pharmacol (2006) 539: 131-8

20. Bartold PM and Haynes DR. Interleukin- 6 production by human gingival fibroblasts. J Periodontal Res (1991) 26: $339-45$

21. Tamura M, Tokuda M, Nagaoka S and Takada H. Lipopolysaccharides of Bacteroides intermedius (Prevotella intermedia) and Bacteroides (Porphyromonas) gingivalis induce interleukin-8 gene expression in human gingival fibroblast cultures. Infect Immun (1992) 60: 4932-7

22. Sismey-Durrant HJ and Hopps RM. Effect of lipopolysaccharide from Porphyromonas gingivalis on prostaglandin $\mathrm{E}_{2}$ and interleukin- $1 \mathrm{~b}$ release from rat periosteal and human gingival fibroblasts in vitro. Oral Microbiol Immunol (1991) 6:378-80
23. Wang PL and Ohura K. Porphyromonas gingivalis lipopolysaccharide signaling in gingival fibroblasts-CD14 and Toll-like receptors. Crit Rev Oral Biol Med (2002) 13: 132-42

24. Ara T, Kurata K, Hirai K, Uchihashi T, Uematsu T, Imamura Y, Furusawa K, Kurihara S and Wang PL. Human gingival fibroblasts are critical in sustaining inflammation in periodontal disease. J Periodontal Res (2009) 44: 21-7

25. Ara T, Fujinami Y, Imamura $\mathrm{Y}$ and Wang PL. Lipopolysaccharide-treated human gingival fibroblasts continuously produce $\mathrm{PGE}_{2}$. J Hard Tissue Biol (2008) 17: 121-4

26. Wang PL, Sato K, Oido M, Fujii T, Kowashi Y, Shinohara $\mathrm{M}$, Ohura $\mathrm{K}$, Tani $\mathrm{H}$ and Kuboki $\mathrm{Y}$. Involvement of CD14 on human gingival fibroblasts in Porphyromonas gingivalis lipopolysaccharide-mediated interleukin-6 secretion. Arch Oral Biol (1998) 43: 687-94

27. Heussen C and Dowdle EB. Electrophoretic analysis of plasminogen activators in polyacrylamide gels containing sodium dodecyl sulfate and copolymerized substrates. Anal Biochem (1980) 102: 196-202

28. Kurata K, Ara T, Kurihara S, Yamada K and Wang PL. LPS-stimulated Apert syndrome gingival keratinocytes show markedly suppressed inflammatory cytokine production. J Oral Biosci (2008) 50: 59-67

29. R Development Core Team. R: A language and environment for statistical computing. R Foundation for Statistical Computing (2008)

30. Gomi K, Yashima A, Iino F, Kanazashi M, Nagano T, Shibukawa N, Ohshima T, Maeda N and Arai T. Drug concentration in inflamed periodontal tissues after systemically administered azithromycin. J Periodontol (2007) 78: $918-23$

31. Takada H, Mihara J, Morisaki I and Hamada S. Induction of interleukin-1 and -6 in human gingival fibroblast cultures stimulated with Bacteroides lipopolysaccharides. Infect Immun (1991) 59: 295-301

32. Okada H and Murakami S. Cytokine expression in periodontal health and disease. Crit Rev Oral Biol Med (1998) 9: 248-66

33. Noguchi K and Ishikawa I. The roles of cyclooxygenase-2 and prostaglandin $\mathrm{E}_{2}$ in periodontal disease. Periodontol 2000 (2007) 43: 85-101

34. Bouwman JJ, Visseren FL, Bouter PK and Diepersloot RJ. Azithromycin inhibits interleukin-6 but not fibrinogen production in hepatocytes infected with cytomegalovirus and Chlamydia pneumoniae. J Lab Clin Med (2004) 144: $18-26$

Received: April 24, 2009 / Accepted: June 5, 2009

Address for correspondence:

Pao-Li Wang

Department of Pharmacology

Matsumoto Dental University

1780 Gobara, Hirooka, Shiojiri

Nagano 399-0781

Japan.

Phone and Fax: ++81-263/51-2102

E-mail: $\quad$ ohhourei@po.mdu.ac.jp 